\title{
Poesia e pensamento em As mãos, a tersa rima (Mapas o Assombro a Sombra).
}

\begin{abstract}
Ana Luísa Alves ${ }^{1}$
RESUMO: Em “As mãos, a tersa rima”, Manuel Gusmão edifica uma poesia problematizadora, consciente do intervalo entre o mundo, o ser e a palavra. Visto como teoria, análise e práxis, o texto poético auto-referencia-se, potencializando a sua estrutura interna ao serviço da imanência, da qual provém a tematização do rigor, do conhecimento do mundo, do diálogo e da intertextualidade, todas elas formas de raciocínio e humanidade.

ABSTRACT: In "The hands, the terse rhyme", Manuel Gusmão builds up a problematizing poetry, aware of the gap between the world, the being and the word. Seen as theory, analysis and praxis, the poetic text is a self reference, in order to potentialize his internal structure at the service of immanence, from which results the subject of accuracy, knowledge of the world, dialog and intertextuality, all of them ways of reasoning and humanity.
\end{abstract}

PALAVRAS-CHAVE: Manuel Gusmão; Mapas o Assombro a Sombra; poética.

KEYWORDS: Manuel Gusmão; Maps The Wonder The Shadow; poetics.

A primeira parte de Mapas o Assombro a Sombra - "As mãos, a tersa rima" 2 - aproxima-se da preocupação reflexiva pela forma como indaga o momento da produção do texto, os seus fenómenos e as suas dúvidas. Sem declarar abertamente um novo programa de poesia sob a forma modelar de uma arte poética, estes treze poemas exercitam, por sua vez, uma análise metapoética. A isto não é alheio o pensamento teórico de Manuel Gusmão, para quem observar, mostrar e transformar são indissociáveis do texto em feitura, tal como se depreende das suas palavras relativas à poesia em geral e à sua produção poética: "Não há representação ou eficácia representativa sem haver ao mesmo tempo

\footnotetext{
1 Doutoranda da Faculdade de Letras da Universidade de Lisboa, Portugal. E-mail: analuisa.ls.alves@gmail.com.

2 GUSMÃO, 1996.
} 
indicação mostrada ou figurada do modo como se representa"3. A tarefa que se segue divide-se em duas fases: em primeiro lugar, justificar textualmente o domínio de uma poética particular em "As mãos, a tersa rima"; e, em segundo lugar, fazer o levantamento das várias problemáticas abordadas e questionar até que ponto todas respondem a uma mesma ansiedade autoral.

Para o primeiro ponto de trabalhos, há que ter em atenção três factores: o título, a estrutura e a imanência. O título desta série de poemas - "As mãos, a tersa rima" - orienta a leitura para o campo da poética. A primeira reacção será a de reconhecer imediatamente uma inscrição de Dante, o criador instituído da terza rima. Embora haja uma tendência para o terceto, na generalidade das composições nega-se o aspecto rimático deste modelo; contudo, numa perspectiva simbólica, não se pode negligenciar o vínculo de perfeição no número três, que não terá uma convicção cristã como na Divina Comédia, mas sim de equilíbrio estrutural, que é, no fundo, o sentido do título "tersa rima". De facto, desta relação paronímica (terza/terça/tersa) resulta a aproximação com a ideia de pureza e de trabalho inquieto sobre a escrita, demanda que se alegoriza nas "mãos" investidas de força criadora por um artífice.

A esta manifestação do raciocínio poético soma-se a ideia de estrutura (geometrizante e delapidada). Não obstante a numeração aparentar uma escolha aleatória, vislumbra-se internamente uma retórica expositiva dos problemas da poesia. Com os primeiros dois poemas - "eis as mãos" e "os dedos esmigalhados" (p. 15-6) -, constróise uma introdução que apresenta sumariamente o ímpeto performador do poema e o seu autor. Com "as mãos fecham a tua cabeça” dá-se início a um novo grupo de duas composições (p. 17-9) relativas ao desejo de expor o mecanismo inaugural do poema, confrontando o antes com o depois. O próximo conjunto poemático (p. 20-6), o mais longo, reúne quatro textos que se evidenciam pela análise da poesia enquanto

3 GUSMÃO, 2005. 
discurso dialógico, cujo resultado foge inevitavelmente da univocidade, cabendo ao autor gerir, se não mesmo, experienciar esta instabilidade de fronteiras e opções. A quarta secção (p. 27-32), composta por três poemas, aborda o tópico representacional, quer pela inscrição poética, quer pela imitação (posta em causa) ou pela escrita de mundos. Conclui-se "As mãos, a tersa rima" com as vertentes temáticas predominantes: a intertextualidade e o dialogismo, correspondendo respectivamente às duas últimas subdivisões (p. 33-8).

Seguindo as pistas de análise propostas por António Guerreiro ${ }^{4}$, a imanência perspectiva-se, por um lado, no modo como o poema se vê a si próprio, e, por outro, nas palavras enquanto revelação. Relativamente ao autocentramento textual, em "As mãos, a tersa rima" surgem várias expressões, que denotam a existência de uma superfície de inscrição poética $^{5}$; à fisicidade do suporte acrescentam-se outros indícios de uma corporalidade poética, como, por exemplo, "as mãos do corpo põem o ilimitado em frases”, "tocas com os dedos uma letra”, “ a teia que as mãos inventam sobre as teclas é uma página" e "como as formas e as cores destas // letras que não cessam"6. Passando para uma óptica mais subjectiva, a inscrição do autor surge como mais um dado do sistema poético, ao ponto de lhe ser consagrada a composição "os dedos esmigalhados” (“n. 1945; m. ...”, p. 16), a par de outras alusões indicadoras da sua acção: “o autor foi ver o tempo" e "É preciso de vez em quando insistir em que alguém está aqui / a falar"7. Consequentemente, "as mãos", presença metonímica do autor, simbolizam o labor (quase artesanal) da poesia, o crescimento de um raciocínio que se faz e se pensa letra a letra. As "mãos" tornam-se centrais neste conjunto de poemas, quer devido à titulação (de secção e individual), quer às recorrentes associações entre a parte prática e as estratégias teóricas, incluídas nos versos “[as mãos] mexem ainda nas

\footnotetext{
${ }^{4}$ GUERREIRO, 1996.

5 "écran em negro / onde a tua voz continua a escrever", "chão da mesa", "mesa de papel recortado acesa e intensa" e "rugoso campo da parede", GUSMÃO, 1996: 18, 21, 27, 27.

6 Idem: 33, 33, 34, 37.

7 Idem: 21, 36.
} 
imagens", "a mão mental experimentava" e "A mão escreve na mente" . Quanto à revelação da palavra, a imagem ígnea assume uma tão forte vitalidade neste grupo de Mapas o Assombro a Sombra, que dissemina os seus sentidos para o campo da sublimação, do excesso, da comunhão e da metamorfose, tal como demonstram os seguintes enunciados: "Uma / labareda clara”, "imagem / que incandesce", "as mãos encontram as figuras do fogo", "Os raios dos dedos põem a girar a hélice: chamas, // chamas fazem a imagem", "Desdobras então os mapas do incêndio"9. Como se processa então a epifania da palavra? Em geral, propicia-se o movimento de abertura e descoberta activa de uma realidade ou consciência (“a outra mão segue a frase sem sombra / no seu caminho à flor do mundo" e "uma letra que se repete e difere e / abre no mundo uma passagem"10), às quais se junta o espanto, ou seja, o assombro "súbito e inesperado"11. Explícita ou implicitamente, a imanência advém da necessidade de tornar presente os passos da elaboração poética, num esforço de mostrar ao retardador os mecanismos mentais, associativos e transfiguradores da relação autormundo ${ }^{12}$; no entanto, não se deve descurar que presentificar é, igualmente, uma forma de doação poética, pelo que "eis as mãos" e "eis o mundo"13 (o advérbio exprime a ideia de movimento de dentro para fora) representam a dádiva da poesia, o que indicia o pendor humanista desta arte poética.

Ante o levantamento de sinais da existência de um discurso autoreferencial e compósito - título, estrutura e imanência -, a palavrachave "mapas" enquadra-se nesta expectativa de orientação e organização, isto é, a demanda teórica insatisfeita - "não concebo a racionalidade como coisa estritamente delimitável e para sempre já

\footnotetext{
8 Idem: $21,27,31$.

9 Idem: 33-4, 15, 18, 24, 33.

10 Idem: 20, 33. Acrescente-se ainda "a minha cabeça abre as tuas mãos”, "a mão abre a noz do silêncio”, "Abres, abro as mãos sobre o écran lunar” (p. 17, 19 e 25).

11 Idem: 22.

12 Idem: 34 - "Há algo que aparece, que vem vindo como uma figura / que ondula na tina escura como uma fotografia em falso".

13 Idem: 15.
} 
feita." 14 - e comprometida com os seus actos constitutivos - "[...] o que importa é essencialmente o modo como jogamos, experimentamos ou inventamos o sentido dessas e de outras palavras"15. Resta agora saber por quais valores a poesia se deve guiar (ou perder, segundo a perspectiva), de modo a realizar-se como texto-problema, como poética de exploração.

\section{Rigor, conhecimento do mundo, diálogo e intertextualidade ${ }^{16}$}

No ensaio "Exactidão"17, Italo Calvino defende que uma das ansiedades da poesia se deve à confusão que perturba as imagens, a linguagem e o mundo. Perante tal cenário, o poeta apura uma subtileza perceptiva, de maneira a arquitectar um modelo de perfeição do real que visa a abstracção e a depuração da palavra (essenciais para o conhecimento), sabendo de antemão que não se trata de uma tarefa absoluta. Em "As mãos, a tersa rima", imagens como "a voz desamparada", o "labirinto" ou o "desenho instável"18 invocam a fragilidade do rigor e demonstram que a escrita constitui um trabalho de persistência, uma procura de equilíbrio ou então um jogo que vive dessa mesma condição. Por exemplo, "figuras voláteis" e "uma paisagem que ondula dentro de uma moldura fixa / no filme em que a orquestra se incendeia"19 remetem-nos imediatamente para a imagem simbólica da chama, a qual revela a ordem formal externa com uma inconstância interna $^{20}$. Uma das estratégias de aproximação ao rigor consiste no recurso à comparação enquanto acto cognitivo possível perante a incapacidade de tradução integral do mundo, induzindo, por vezes, para

\footnotetext{
14 GUSMÃO, 1994: 235.

15 GUSMÃO, 2005.

16 "obsessão com a construção de cada livro, o rigor da composição verbal"; "não desistir da veemência, da imagem alucinada"; "a heterogeneidade de registos e níveis discursivos"; "formas ou as entoações da poesia narrativa”, GUSMÃO, 2004.

17 CALVINO, 1990: 71-97.

18 GUSMÃO, 1996: 25, 27, 27.

19 Idem: 33, 25.

20 CALVINO, 1990: 88.
} 
o campo do imaginário e da acumulação ${ }^{21}$. Levada ao extremo, a "fala ainda / difícil”22 agudiza-se na tendência para a pronominalização ambígua e a sintaxe não convencional ${ }^{23}$. Não se pense, todavia, que a ideia de precisão fica arredada desta poética. Na verdade, o campo semântico do rigor ${ }^{24}$ percorre todo o grupo poemático, para reforçar o papel obstinado do poeta à procura da "ardente perfeição das coisas" 25 . O choque parte sobretudo do esforço do sujeito poético face à instabilidade que, de facto, é a própria condição do mundo; trata-se fundamentalmente de entender o rigor como assunção das contingências necessárias à sublimação da palavra.

Indissociável de qualquer reflexão metapoética, o conhecimento do mundo integra tradicionalmente o desejo de mestria, que se pauta pela transposição do real externo para o papel. Todavia, aquando da menção da poesia de Francis Ponge, Italo Calvino recorda que esta é "uma batalha com a linguagem para a transformar na linguagem das coisas, que parte das coisas e volta para nós com toda a carga humana que tínhamos investido nelas"26; logo, o pensamento estético tem provado que os processos cognitivos ultrapassam as expectativas e recorrem à abertura deste intervalo eu-mundo, para validar as novas opções poéticas centradas na vivência subjectiva, vendo neste hiato uma fonte de análise, exploração e razão na poesia.

Em “As mãos, a tersa rima”, Manuel Gusmão vê o mundo sob a perspectiva da "ardente perfeição das coisas" e sob a sua "sombra"27, o que contamina a linearidade da leitura do real; este vai beber a paixão e

\footnotetext{
21 "acena / como se o touro fosse voar", "olhas em frente para a música fora do livro: é como se / visses a hora da noite", "as mãos do corpo põem o ilimitado em frases / como se o rigor acometesse os cavalos selvagens" e "Uma passagem / que é como uma entoação, uma mudança na voz, uma inclinação / impossível que vem ao corpo" GUSMÃO, 1996: 18, 23, 33, 34 .

22 Idem: 20.

23 Cf. Idem: 21, 23 (“o corpo imóvel danças”).

24 "tentas", “continua a escrever”, "retina intensa”, "medir”, "hesita”, “as frases prolongam-se até quase / doer”, Idem: 17, 18, 20, 21, 21, 35.

25 Idem: 21.

26 CALVINO, 1990: 93.

27 GUSMÃO, 1996: 21.
} 
a incerteza que o mundo oferece e, a partir daí, reescrever a comunhão com o vivo.

O caso do poema "Na metade da direita a árvore" (p. 28-31) é deveras interessante, uma vez que "descreve” o quadro Prazer (1927), de René Magritte. O cunho ecfrástico é notório, no que diz respeito ao acompanhamento da visualização da obra, dado que se fornece ao leitor pistas orientadoras de reconhecimento espacial, cromático e das acções. Porém, a marca da subjectividade, que idealmente lhe deveria ser alheia, entra no poema, sendo sintetizada na frase "Por trás não te escrevi nada / mas contei-te a suave alucinação / em que aparecias // tão próxima e tão estranha”, que termina a composição. Devaneio adequa-se sem dúvida à estética surrealista de Prazer, aqui pela via da dúvida quanto à origem do choque; mas, na óptica ecfrástica, devaneio insinua a presença crítica e interventiva da observação, que tem consciência do intervalo com o objecto - "moldura" e "[a] rapariga [...] // alheada de nós e concentrada n' "o prazer" - , que faz digressões, e que simula o diálogo ${ }^{28}$. Por tudo isto, "Na metade da direita a árvore" protagoniza aqui o salto cognitivo e a consequente, assim como impossivel, neutralidade no acto de aceder ao mundo.

Quanto a esta tendência deformatória, o intervalo entre o eu e o real ("[o] mundo antiquíssimo e perpétuo"29), inferido pelo seu campo semântico "levitando", "fronteira", "passagem" e "mudança" 30 , favorece a elaboração de diversos cenários, pelo invocar de ambientes díspares e vagos, como, por exemplo, a confusão - "um vago tumulto de mundos" , o furor - "pássaro crispado gravando no olhar do mundo uma retina intensa" - e o imaginário - "sistema de portas / de corredores que abrem sobre corredores na água”31. De facto, a ausência de limites (não se incluir num sistema fechado) induz a uma mudança no paradigma cognitivo, pois, se antes o real precedia a nomeação, agora é a

\footnotetext{
28 "[o] pinhal / antigo em que a criança corre à procura"; "é o dia dos teus anos" Idem: $28,30$. 29 Idem: 19.

30 Idem: 19, 20, 33, 34.

${ }^{31}$ Idem: 20, 20, 34.
} 
nomeação que constrói o real, como se pode asseverar na frase "a praia é o que nasce da inscrição" 32 .

Efectivamente, a alucinação, explicitada já "Na metade da direita a árvore”, como em diversas ocasiões ${ }^{33}$, é o sintoma da instabilidade provocada pelo abismo entre mundos. A sua fragilidade proporciona novas alternativas e experiências, que englobam a estética surreal (a qual torna notória a ligação com poetas como Herberto Hélder ou Luiza Neto Jorge) pela via do absurdo, das associações insólitas e, até mesmo, das imagens apocalípticas ${ }^{34}$. Ao nível rítmico, o devaneio brota no poema "Abres, abro as mãos" (p. 25-6) por meio de uma cadência encantatória, apoiada na repetição, comparação, quiasmo e sonoridade:

um avião belo como um avião

belo como um avião

que canta a tempestade que vem ao verão como um avião belo de dorso luzente e excepcional.

É na conclusão de "As mãos, a tersa rima” que se comprova a especificidade do campo literário e do trabalho da palavra na formação do real, quando nomeia a "catacrese"35 como figura de conhecimento metafórico, que, apesar de relacionada com o abuso da língua, não deixa de ser sinal da personalização, criatividade e esforço associativo a partir do mundo reconhecível, o que se coaduna com as seguintes palavras de Manuel Gusmão: "Na poesia o que pode acontecer é que o

\footnotetext{
32 Idem: 20.

33 "a pintura que delira" e "Tenho a boca alucinada" - Idem: 32, 38.

${ }^{34}$ Idem - cf. p. 18 ; "dentro já vêem-se-lhes os ossos eléctricos / fazendo as ondas de um pequeno mar visto de cima", p. 20, "e a terra recordava-se murmurante / das raízes das árvores eléctricas / em cujos ramos brilhavam os peixes / profundos", p. 31 , "escreve as suas figuras voláteis / como borboletas transparentes", p. 33 e "Uma tempestade eléctrica no céu da boca e na câmara escura", p. 38; "aureolada pelo napalm" e "os barcos navegam uma noite branca / que se ergue como um monte iluminado / por monstruosas flores irregulares // em cruz e em espiral à tua espera", p. 32.

35 Idem: 38.
} 
poema, enquanto mundo, dê a pensar a sua plurissignificação como correspondente à inesgotabilidade do real" 36 .

Com a confirmação do factor humano e da disparidade de mundos na poesia, o diálogo, ponte de comunicação intersubjectiva, cumpre esse elo de ligação entre o real e o sujeito poético. Não raro, encontram-se clarividências do dialogismo, sobretudo nas interpelações em discurso directo, indirecto livre e solilóquio ${ }^{37}$, no corpo participante ${ }^{38}$, e nos actos de comunhão ${ }^{39}$.

Por meio do dialogismo, estimula-se o impulso associativo das "máquinas desejantes" de Delleuze e Guattari ${ }^{40}$, na medida em que há uma ansiedade perante um mundo fragmentado entre continuidades e descontinuidades. Através do movimento erótico (Georges Bataille ${ }^{41}$ ), a referida dispersão do real acende-se em desejo impetuoso de alcançar a unidade perdida - a comunhão dialógica. As motivações do ser para a comunicação íntima, comunitária, verbal ou corporal ocorrem desta recusa do isolamento; por conseguinte, e tomando o raciocínio de Paul Valéry, a literatura obriga-se não só a ser diálogo do autor com a sua própria obra em jeito de crítica, assim como diálogo com o leitor, tudo isto justificado através da máxima "nada vale o que só para um vale" ${ }^{42}$. Resumindo, o autor-emissor demonstra que o dialogismo espelha o raciocínio e a introspecção, no sentido da formação poética, ciente e coerente com a disparidade do mundo, das linguagens e dos seres.

No poema "Era como se quem falasse" (p. 36-8), declara-se uma atenção especial ao diálogo e à sua dimensão intersubjectiva, dado que "Ninguém fala separadamente". Este aspecto poético desenvolve-se sob duas frentes: o eu que se desdobra e o corpo que se une à palavra

36 GUSMÃO, 1994: 242.

37 GUSMÃO, 1996 - "não me tens aqui? diz ele", p. 24, "é como se tivesses dito: vem cá"p. 17; "Estaria já então escrevendo com a mão mental?, p. 23.

38 "cabeça", "mãos", "rosto", "membros", "boca" e "língua", idem: 17, 19, 22, 23, 37, 38.

39 "beijo", "abre", "vem”, "sobem ao encontro", "fluxo e refluxo", "regressam”, "inclinaste", "comércio", "amor", "viaja”, "espasmo" e "passar", idem: 16, 17, 17, 19, 19, 21, 23, $26,36,31,34,34$.

40 DELEUZE e GUATTARI, 1995.

${ }^{41}$ BATAILLE, 1988.

42 VALÉRY, 1995: 85. 
(levando ao mundo verbalizado). Quanto ao primeiro ponto, distinguemse dois sujeitos explícitos no texto - o eu e o tu -, sendo o primeiro a voz autoral, ao passo que o segundo é apenas pronominalizado (ou surge através das formas verbais; é de salientar que isto se generaliza ao conjunto poético): "mas o ar não respondesse ao que te escuto". Não obstante o diálogo ganhar contornos de discurso directo livre - "Assim, isto; vês: isto?" -, há indicações que sustentam a dúvida quanto à existência de dois seres em comunicação: o enunciado "tu escreves" estabelece logo uma união entre o autor e o outro pela via do labor poético; no início do texto, "Era como se quem falasse visse pela boca" é proferido pelo eu, no fundo, sobre a sua própria acção, e será depois reforçado - "E tu respondes: é como se visses pela boca" - com a passagem para a voz na segunda pessoa, assemelhando-se a um desdobramento do eu; no final da composição, os quatro últimos versos $^{43}$ fecham totalmente o diálogo sobre a primeira pessoa devido à auto-refencialidade do discurso recursivo e à ideia de circuito fechado. A palavra "labirinto" (repetida nesta última parte) sintetiza, então, a introspecção analítica e labor de juízos, os quais transformam o diálogo num monólogo favorável à reflexão metapoética.

O corpo é outra forma de comunicação produtiva neste poema. Os versos " Tenho a boca alucinada com a tua lingua na minha lingua na tua boca" e “ A voz, sabes, desliza de uma a outra boca, vês?" movimentam o eros combinatório ${ }^{44}$ a partir dos órgãos de afectividade e verbalização, de maneira a sugerir a componente física da palavra e a sua afectação: "E a tua língua molha a raiz da minha voz que se desmorona”. Tal como esperado, a acção do corpo interfere na composição poética, pelo acompanhamento da narratividade e pela intromissão activa, que visa o rigor e a sua perturbação

43 GUSMÃO, 1996 - "Talvez possas ouvir-me o que me dizes dizer-te: / - cerca-me com o teu labirinto, tu // - põe à minha volta, a toda a volta, o teu labirinto / - tu, cerca-me com o teu labirinto, eu", p. 38.

44 Muitos textos metapoéticos de Luiza Neto Jorge recorrem ao corpo para expor a fenomenologia do poema em labor, o que resulta numa visão "obscena" (o que está escondido) da poesia. 
simultaneamente ${ }^{45}$. O efeito sente-se sobretudo na percepção do mundo, que deixa de ser feita pelos sentidos (numa perspectiva meramente receptora), mas pela palavra-corpo-actuante - "é como se visses pela boca, pelas mãos" -, isto é, que cria e transfigura o mundo, mudando o conceito de representação. É do diálogo entre o sujeito e a palavra que brota a inscrição do real no poema e sem ele "não haveria / nenhuma voz sobre as dunas, os juncais, as pedrarias do mundo". Movidos pelo desejo de rejeição do silêncio, o corpo e a escrita interagem, quais organismos complexos que lutam pela vitalidade contra o descontínuo.

O último tópico desta poética, a intertextualidade, segue a linha de raciocínio do diálogo, todavia compreendendo outras áreas de trabalho, outras linguagens. Até este momento, já se mencionou um caso de comunicação interartes, o poema "Na metade direita a árvore" (p. 28-30), em que se descreve o quadro Prazer de René Magritte, recorrendo a uma fidelidade visual, que permite, no entanto, a participação do sujeito poético. Já numa perspectiva geral, em "As mãos, a tersa rima” detectam-se referências inalteradas, quase sempre fragmentárias, as quais compreendem autores como Gomes Leal e Camões, ou textos como o Requiem ${ }^{46}$. Outras há em que se operaram adaptações lexicais e semânticas; neste rol incluem-se Cesário Verde, Álvaro de Campos, Sá de Miranda e Camões ${ }^{47}$ (é de salientar que muitas destas citações são assinaladas pelas aspas, sem que seja identificada a sua origem). Segue-se o campo das alusões, que remetem para a literatura ("Autopsicografia”, de Fernando Pessoa), a mitologia

\footnotetext{
45 "põe as mãos aqui; no écran onde passa o filme", "Mexes as mãos à procura do som das falas" e "[as mãos] fazem que não há paz entre os versos, entre as estrofes / entre cada letra do nome, que [me] põe a voz em movimento", idem: 36, 37, 36.

46 Idem - "o dorso luzente / e excepcional de um peixe", p. 25; "estavas posta em sossego", p. 24 e "um seco, fero e estéril monte", p. 33; "Promisisti / promisisti et semini ejus", p. 23.

47 Idem - "ardente perfeição das coisas", p. 21; “[o] mundo antiquíssimo e perpétuo", p. 19; "Uma neve co'a tarde cai, devagar, sobre a paisagem", p. 22; "já diante dos olhos te voavam imagens e fantásticas / pinturas, exercícios do pensamento por figuras”, p. 34.
} 
(Ícaro), a música (piano), o cinema, a fotografia e a dança ${ }^{48}$, de modo a incitar ao diálogo entre várias ópticas sobre a dispersão do real. Também se recria o labor da música no poema "Curtas e lábeis as mãos do corpo" (p. 33-35), que acompanha os movimentos e a leitura rítmicomelódica do piano. Devido à proliferação deste tipo dados, muitas vezes é fabricada a ilusão da citação, de um filme, de uma imagem, não com uma atitude de eruditismo, mas sim para gerar cenários possíveis ${ }^{49}$.

$\mathrm{Na}$ entrevista de Floriano Martins ${ }^{50}$, Manuel Gusmão justifica a abundância do intertexto na sua obra, no sentido de a palavra particular passar a comum, como legado responsável contra o silêncio, a favor do diálogo, ao encontro da excelência e do sublime. Tal como no diálogo, há uma aposta na transversalidade de saberes e no aprofundamento quer contemplativo quer interventivo. Mais do que uma opção estilística, a intertextualidade revela uma comunhão de valores e linguagens, possibilitando associá-la ao sentimento utópico que subjaz a este grupo poético. Não obstante a euforia se destacar em "alegria", "esperança" e "promessa" 51, há um contrapeso bastante pragmático: a inevitabilidade da "morte", por vezes verbalizada como "esquecimento" e "silêncio" 52 . Não se quer com estes dados afirmar que se assiste a um movimento disfórico nesta poesia.; antes uma consciencialização vigilante, que racionaliza a evidência e o hipotético: "alegria mortal", "fragmentos de uma alegria", "uma promessa que compromete sem garantias”, "a utopia [...] que é aqui e agora” e "cantada do mais alto do murmúrio" 53. São estes estados paradoxais que instigam a voz poética a viver uma positividade contingencial, patente nos sinais de renascimento, resistência e impeto ${ }^{54}$ que

48 Idem - "comboio de criança", p. 31; "queda que voa", p. 19; "suites para violoncelo", p. 26 e "Curtas e lábeis as mãos do corpo", p. 33-5; "no écran onde passa o filme", p. 37; "ondula na tina escura como uma fotografia em falso", p. 34; "e isso dança”, p.34.

49 Cf. Idem: 32.

50 GUSMÃO, 2004.

51 GUSMÃO, 1996: 35, 36.

52 Idem: 37.

53 Idem: 25, 37, 23, 35.

54 Idem - "beijo-te como se nascesse", p. 16; "não há silêncio na minha cabeça a morrer" e "no mais / intenso do que é intenso", 37. 
confirmam as palavras de Manuel Gusmão: “enquanto nos perdemos nos poemas, ou poema a poema, isso é sinal de que ainda estamos vivos" 55 .

Para terminar, “As mãos, a tersa rima”, de Manuel Gusmão, não é uma arte poética convencional, não constitui um modelo rígido, nem exige uma única lei da palavra. A sua linha de pensamento defende a vivência do mundo e do espanto perante a riqueza de perspectivas que vai absorvendo, imaginando e construindo. A sua poética abre-se à experiência da alucinação, do quotidiano e do outro; instiga à contemplação da palavra desafiadora e difícil; deseja utopicamente a unidade dentro de um labirinto de contingências; cuida do humano plural, comunitário e resistente contra as sombras da morte silenciosa; e quer-se como teoria, análise e prática de uma poesia consciente, porque comprometida com o ser, a linguagem e o real. Por fim, "As mãos, a tersa rima” ensina a saber estar no desassossego da poesia:

O que permite que a poesia possa ser esse trabalho de construção antropológica aberta é, no fundo, radicalmente, do ponto de vista de uma teoria da linguagem, o ela ser apropriação, re-aprendizagem, exploração dos possíveis da linguagem como componente histórica e transhistórica da antropogénese. 56

\section{Referências Bibliográficas}

BATAILLE, Georges, O Erotismo. Lisboa: Edições Antígona, 1988.

CALVINO, Italo, "Exactidão", in Seis Propostas para o Próximo Milénio. $4^{\mathrm{a}}$ ed. Lisboa: Teorema, 1990 (p. 71-97).

DELEUZE, Gilles e GUATTARI, Félix, $O$ Anti-Édipo - Capitalismo $e$ Esquizofrenia. Lisboa: Assírio \& Alvim, 1995.

GUERREIRO, António. A escrita, o espanto (recensão crítica de Mapas o Assombro a Sombra). In Expresso-Cartaz, 5 abr. 1996.

GUSMÃO, Manuel. Da poesia como razão apaixonada. 3. In BASÍlLIO, Kelly e GUSMÃO, Manuel (orgs.). Poesia \& Ciência. Lisboa: Edições Cosmos, 1994 (p. 235-248).

GUSMÃO, Manuel, Mapas o Assombro a Sombra. Lisboa: Editorial Caminho, 1996.

55 GUSMÃO, 2005.

56 GUSMÃO, 1994: 246. 
GUSMÃO, Manuel. Diálogo com Manuel Gusmão" (entrevista de Floriano Martins). Agulha. Revista de Cultura [online]. 2004, no. 39 [citado em 2008-02-29]. Disponivel em: <http://www.revista.agulha.nom.br/ag39gusmao.htm>

GUSMÃO, Manuel. Alucinação e rigor como princípios de uma poética (entrevista de

Ana Marques Gastão). In Diário de Notícias, 21 fev. 2005.

VALÉRY, Paul, Discurso sobre a Estética. Poesia e Pensamento Abstracto. Lisboa: Vega, 1995. 